\title{
NITROGÊNIO E POTÁSSIO EM BANANEIRA VIA FERTIRRIGAÇÃO E ADUBAÇÃO CONVENCIONAL-ATRIBUTOS QUÍMICOS DO SOLO ${ }^{1}$
}

\author{
LUIZ ANTONIO JUNQUEIRA TEIXEIRA², WILLIAM NATALE ${ }^{3}$, JOSÉ EMÍLIO BETTIOL NETO ${ }^{4}$, \\ ANTONIO LÚCIO MELLO MARTINS 5
}

RESUMO - Realizou-se um experimento em Pindorama (SP), no qual se avaliaram os efeitos da fertirrigação e da adubação convencional com $\mathrm{N}$ e $\mathrm{K}$ em alguns atributos químicos de solo sob cultivo com bananeira, durante dois ciclos de produção. Avaliaram-se a disponibilidade e a movimentação de nutrientes ( $\mathrm{P}, \mathrm{K}, \mathrm{Ca}$ e $\mathrm{Mg}$ ) no perfil do solo, bem como outros atributos químicos (matéria orgânica, acidez e saturação por bases), por meio de amostragens realizadas na implantação do experimento e ao final do primeiro e segundo ciclos de produção. Os principais efeitos dos tratamentos foram no $\mathrm{pH}$ do solo e no teor de $\mathrm{K}^{+}$trocável. A adubação, tanto aplicada via fertirrigação como na forma convencional, implicou incrementos na acidez do solo, principalmente até $20 \mathrm{~cm}$ de profundidade. Observou-se que o impacto da adubação via fertirrigação no $\mathrm{pH}$ do solo foi proporcional à dose. A adubação convencional também causou decréscimo no pH, especialmente na região mais próxima das plantas, refletindo o efeito da aplicação localizada dos fertilizantes. A aplicação de adubo sólido na superfície do solo determinou significativo acúmulo de $\mathrm{K}$ nas camadas até $20 \mathrm{~cm}$ e na região mais próxima ao pseudocaule das plantas. Os efeitos da adubação via fertirrigação foram mais difusos, visto que os adubos são espalhados numa área de solo maior do que a coberta pela adubação convencional.

Termos para indexação: banana, análise de solo, cloreto de potássio, nitrato de amônio, Musa spp.

\section{NITROGEN AND POTASSIUM APPLICATION ON BANANA PLANT BY FERTIRRIGATION AND CONVENTIONAL FERTILIZATION - SOIL CHEMICAL PROPERTIES}

\begin{abstract}
A field experiment was carried out in Pindorama (Sao Paulo State, Brazil) in which it was evaluated the effects of N and $\mathrm{K}$ application through fertirrigation and conventional fertilization on soil chemical properties in a banana plantation, during two cycles of production. Nutrient ( $\mathrm{P}, \mathrm{K}, \mathrm{Ca}$ and $\mathrm{Mg}$ ) availability and movement in soil profile and some chemical properties (organic matter, $\mathrm{pH}$ and base saturation) were evaluated through samples carried out in the experiment implantation and at the end of the first and second production cycles. The most important treatment effects were on soil $\mathrm{pH}$ and on exchangeable K. Fertilizers, applied by fertirrigation or conventional fertilization, increased soil $\mathrm{pH}$ specially in soil layer depth of 0 to $20 \mathrm{~cm}$. It was observed that the impact of $\mathrm{pH}$ soil fertilization via fertirrigation was proportional to fertilizer rate. The conventional fertilization also caused a $\mathrm{pH}$ decrease on soil, and it was more intense near the plants, reflecting the effect of fertilizer local application. The application of solid fertilizer on the soil surface determined a significant accumulation of exchangeable $\mathrm{K}$ on layers until the depth of $20 \mathrm{~cm}$ and in the region nearer the plant pseudo-stem. The effects of fertirrigation on soil chemical properties were more diffuse because fertilizers were spread in a larger area than the application of conventional fertilization.
\end{abstract}

Index terms: banana, soil analysis, Potassium chloride, Ammoniun nitrate, Musa spp

\section{INTRODUÇÃO}

A sustentabilidade dos cultivos de bananeira tem sido associada às condições de fertilidade do solo por vários autores. Quantidade e qualidade da produção, crescimento e desenvolvimento das plantas, suscetibilidade a pragas e doenças, e rentabilidade da atividade são alguns dos aspectos fundamentais da bananicultura que dependem do estado nutricional das plantas. A exportação de nutrientes pela colheita dos cachos, perdas por lixiviação e escorrimento superficial, bem como acidificação do perfil do solo, reforçam a importância do manejo cuidadoso da fertilidade como condição para manutenção de rendimentos elevados ao longo do tempo (Jacob \& Uexküll, 1958; Cunha \& Fraga Jr., 1963; Gallo et al.,1972; Uexküll, 1985; Godefroy \& Dormoy, 1990; Teixeira et al., 2001; Teixeira, 2005).
Mudanças nos padrões do agronegócio têm transformado a competitividade numa questão de sobrevivência para os bananicultores, com o mercado exigindo frutos de qualidade e baixo custo de produção, o que implica otimizar o uso de recursos como mão-de-obra e insumos. Outra característica que vem sendo incorporada aos sistemas de produção de frutíferas é a busca por alternativas tecnológicas que minimizem o impacto ambiental da atividade. Nas recentes normas para a Produção Integrada de Frutas (PIF) no Brasil (Andrigueto \& Kososki, 2002), constam como "práticas obrigatórias", entre outras, a aplicação de fertilizantes conforme a necessidade das culturas e a adoção de técnicas que minimizem perdas de nutrientes.

A fertirrigação é a prática de aplicar fertilizantes dissolvidos na água de irrigação de forma contínua ou intermitente, possibilitando diminuir perdas de nutrientes do sistema solo-

\footnotetext{
${ }^{1}$ (Trabalho 161-2006). Recebido em 19-10-2006. Aceito para publicação em 13-02-2007. Trabalho realizado com o apoio da FAPESP (Projeto 01/09976-3). ${ }^{2}$ Pesquisador do Centro de Solos e Recursos Ambientais - IAC/APTA, Cx. Postal 28, 13012-970, Campinas-SP, teixeira@iac.sp.gov.br

${ }_{3}^{3}$ Professor Adjunto do Depto. de Solos e Adubos-FCAV/Unesp. Bolsista do CNPq. Jaboticabal-SP, natale@fcav.unesp.br

${ }^{4}$ Pesquisador do Centro de Fruticultura - IAC/APTA. bettiolneto@iac.sp.gov.br

5 Pesquisador da APTA Regional Centro Norte. Pindorama- SP, Imartins@aptaregional.sp.gov.br
} 
planta e aumentar a eficiência da adubação. Para bananeira, há vários relatos de que a fertirrigação permite reduzir a quantidade de adubo aplicada em relação à adubação convencional, sem perdas na produção de frutos (Stewart et al., 1998; Srinivas, 1997; Hagin \& Tucker, 1992).

Buscou-se, com este trabalho, determinar alterações em atributos químicos de um solo sob cultivo de bananeira em função da aplicação de N e K por meio de adubo sólido na superfície do solo e via fertirrigação durante dois ciclos de produção.

\section{MATERIAL E MÉTODOS}

O experimento foi implantado na Estação Experimental de Pindorama, localizada na região noroeste do Estado de São Paulo (48 $55^{\circ} \mathrm{W}$ e $21^{\circ} 13^{\prime}$ 'S). Conforme classificação de Köppen, o clima enquadra-se no tipo Aw, definido como tropical úmido com estação chuvosa no verão e seca no inverno. O balanço hídrico indica serem os meses mais secos os de julho, agosto e setembro, e haver considerável excedente hídrico principalmente de janeiro a março (Lepsch \& Valadares, 1976). Na Figura 1, é apresentada a precipitação mensal medida na área experimental, no período de novembro de 2002 a maio de 2005.

De acordo com o Mapa Pedológico do Estado de São Paulo (Oliveira et al., 1999), o solo recebe a denominação de Argissolo Vermelho-Amarelo eutrófico abrúptico, A moderado, textura arenosa/média - Unidade Pindorama. Esse tipo de solo, bem como o clima do local da experimentação são bastante comuns nas áreas do Planalto Paulista, onde a bananicultura está se expandindo.

Foi empregado o delineamento experimental de blocos casualizados, com seis repetições. Os tratamentos constaram de frações da recomendação de adubação convencional de nitrogênio e potássio aplicada via fertirrigação e aplicação da dose recomendada via adubo sólido na superfície do solo sob sequeiro e com irrigação (Tabela 1). As doses de nitrogênio (350 kg de $\mathrm{N}$ ha ${ }^{1}$ ano $^{1}$ ) e de potássio ( $400 \mathrm{~kg} \mathrm{de}_{2} \mathrm{O}$ ha ${ }^{1}$ ano $^{1}$ ) foram calculadas de acordo com atributos do solo e produtividade esperada, seguindo as recomendações do Boletim 100 do Instituto Agronômico (Teixeira et al., 1997).

As unidades experimentais foram compostas por 16 plantas, sendo quatro consideradas para as avaliações (plantas úteis). O espaçamento foi de $2 \times 2,5 \mathrm{~m}$, resultando numa população de 2.000 plantas ha ${ }^{1}$ (Figura 2).

Em setembro de 2002, aplicou-se calcário dolomítico, visando a elevar a saturação por bases (V\%) para 60\%. Em dezembro, as plantas foram estabelecidas, empregando-se mudas micropropagadas in vitro da variedade Nanicão (Grupo AAA, subgrupo Cavendish). Para o plantio e práticas de manejo do bananal, foram seguidas as recomendações descritas por Moreira (1999).

As doses aplicadas via fertirrigação foram obtidas por meio da montagem de dois conjuntos de linhas principais, derivações e laterais para conduzir de forma independente água e água + adubo. As diferentes quantidades de adubo aplicadas via água de irrigação foram obtidas combinando-se três microaspersores, parte deles aplicando uma mistura de água + adubo e outra, somente água, conforme o tratamento. Para cada duas plantas (Figura 2), foi montado um conjunto de emissores com vazão total de $110 \mathrm{~L} \mathrm{~h}^{-1}$ e $100 \%$ da área molhada. Antes das primeiras aplicações de fertilizantes via água de irrigação, fez-se a calibração e a regulagem do sistema injetor. $\mathrm{O}$ manejo da irrigação deu-se a partir de dados meteorológicos (evaporação do tanque Classe A e precipitação) coletados próximos à área experimental e do acompanhamento do conteúdo de água do solo por tensiometria $(20$ e $60 \mathrm{~cm}$ ). As aplicações (lâmina e turno de rega) foram realizadas de acordo com o recomendado para a cultura em Doorenbos \& Kassam (1979). O intervalo máximo entre regas foi de três dias.

A aplicação dos fertilizantes, nitrato de amônio e cloreto de potássio como fontes de $\mathrm{N}$ e $\mathrm{K}$, respectivamente, seguiu as indicações de Frizzone e Botrel (1994). A fertirrigação foi aplicada quinzenalmente, e a adubação via solo, fracionada em quatro aplicações anuais. Além dos tratamentos com diferentes doses de $\mathrm{Ne} \mathrm{K}$, foram aplicados $100 \mathrm{~kg} \mathrm{ha}^{-1} \mathrm{de}_{2} \mathrm{O}_{5}(50 \%$ em área total e incorporado e $50 \%$ no plantio, como superfosfato simples); 4,0 $\mathrm{kg} \mathrm{ha}^{-1}$ de Zn (no plantio, como sulfato de Zn) e 3,0 kg ha-1 de B (no plantio, como bórax).

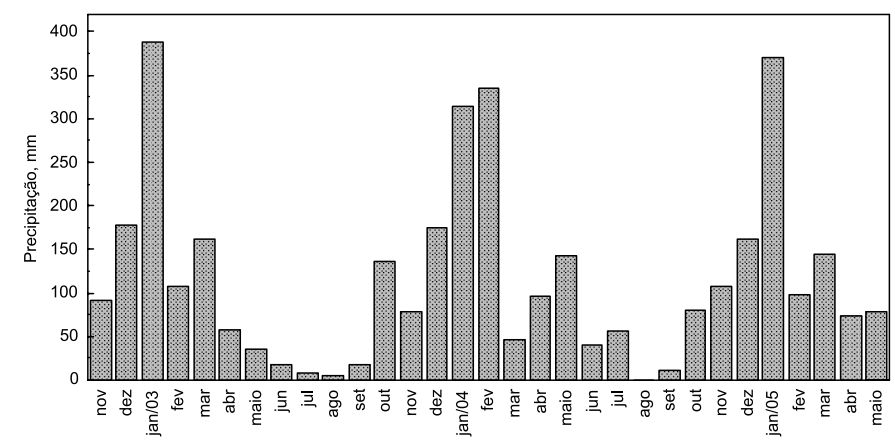

FIGURA 1 - Precipitação medida na área experimental de novembro de 2002 a maio de 2005.

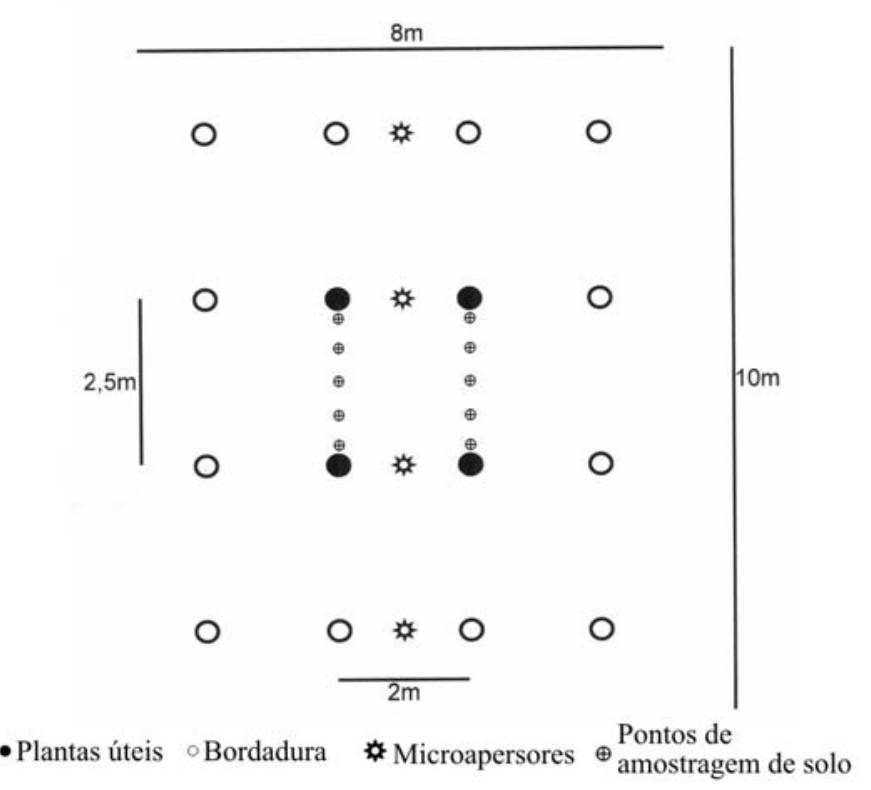

FIGURA 2 - Croqui de uma parcela. 

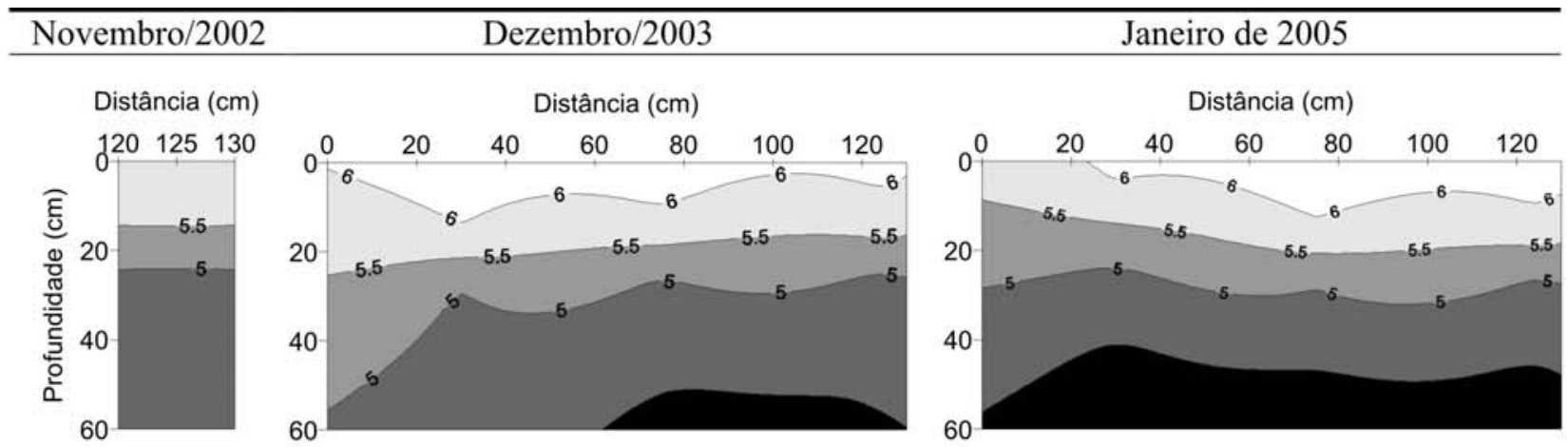

$\mathrm{pH} \mathrm{em} \mathrm{CaCl}_{2}$

Irrigado sem aplicação de $\mathrm{N}$ e K
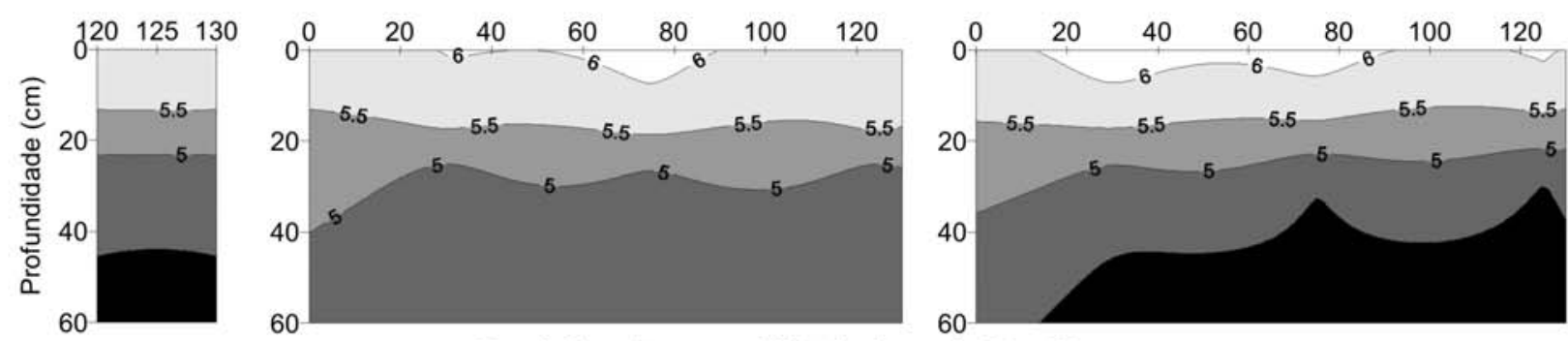

Fertirrigação com $40 \%$ da dose de N e K
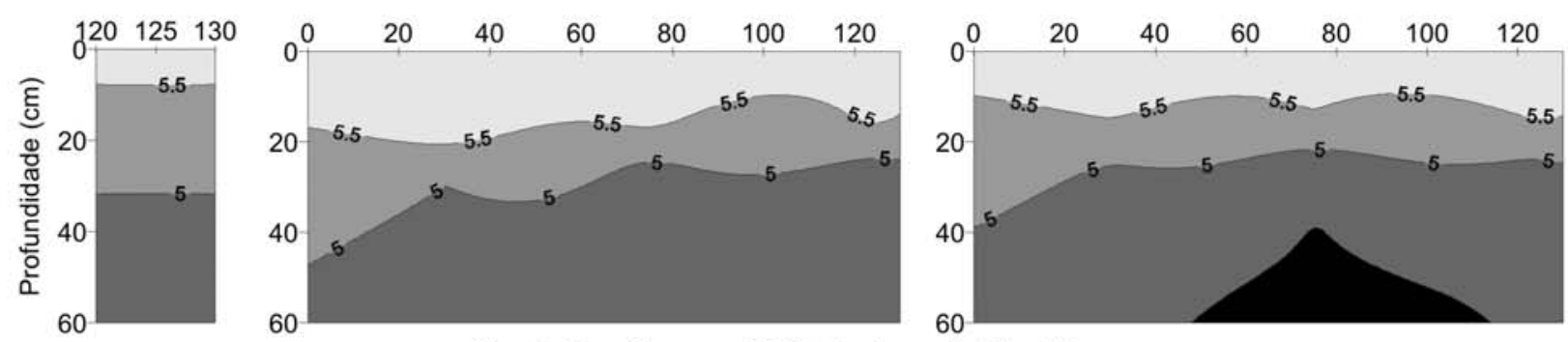

Fertirrigação com $80 \%$ da dose de N e K
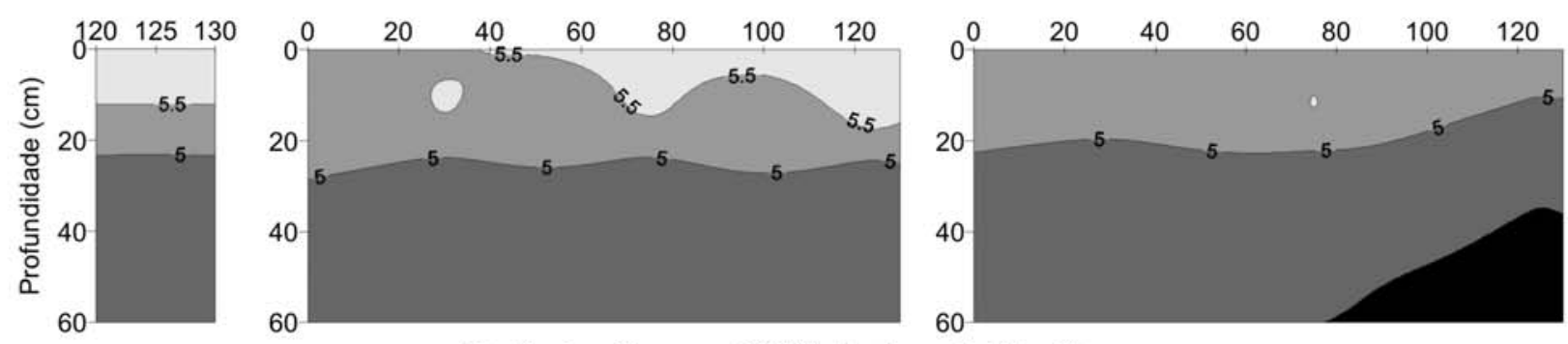

Fertirrigação com $120 \%$ da dose de N e K
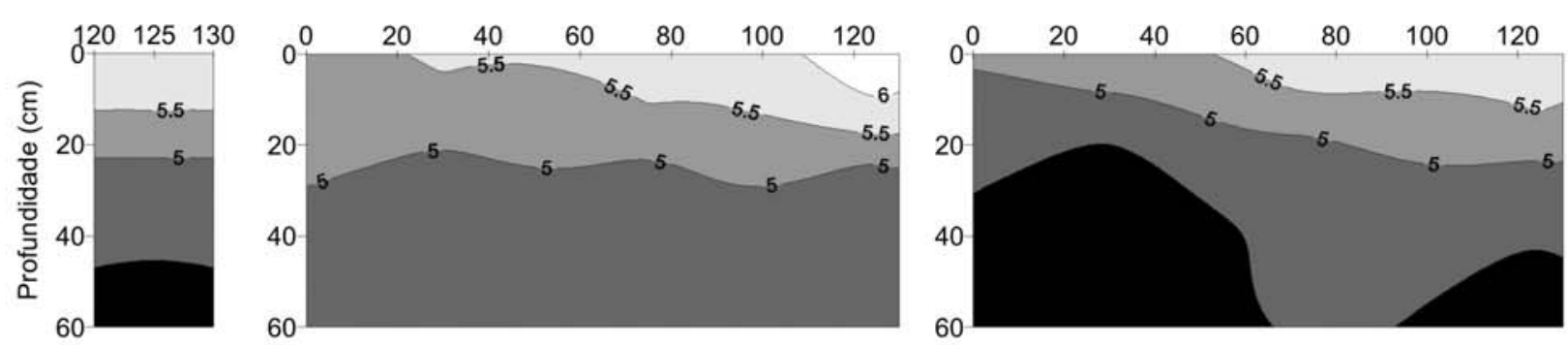

Irrigação com $100 \%$ da dose de $\mathrm{N}$ e K aplicado via solo

FIGURA 3 - pH $\left(\mathrm{CaCl}_{2}\right)$ do solo nas parcelas sob irrigação em função dos tratamentos, camada amostrada (eixo vertical, cm) e distância da planta-mãe(eixo horizontal, $\mathrm{cm}$ ). 
Antes do plantio, coletaram-se amostras compostas (quatro subamostras) de todas as parcelas em quatro camadas de solo: 0 a $5 \mathrm{~cm} ; 5$ a $20 \mathrm{~cm} ; 20$ a $40 \mathrm{~cm}$ e 40 a $60 \mathrm{~cm}$ (Tabela 2). Por meio desta amostragem, caracterizaram-se as unidades experimentais de modo individualizado, permitindo, com o decorrer do trabalho, que fosse estimada a evolução dos atributos químicos em função dos tratamentos. Em dezembro de 2003 e em janeiro de 2005, fez-se amostragem mais detalhada, visando a detectar o efeito dos tratamentos no perfil do solo. Foram coletadas amostras compostas de todas as parcelas em quatro camadas: 0 a $5 \mathrm{~cm} ; 5$ a $20 \mathrm{~cm} ; 20$ a $40 \mathrm{~cm}$ e 40 a $60 \mathrm{~cm}$; e em três distâncias da planta-mãe: $30 \mathrm{~cm}, 75 \mathrm{~cm}$ e a $125 \mathrm{~cm}$ (Figura 2). Atributos químicos do solo foram analisados segundo métodos descritos por Raij et al. (2001).

Os dados coletados foram tabulados e analisados estatisticamente, empregando-se o módulo GLM do Statistical Analysis System (SAS). Os resultados foram submetidos à análise de variância, sendo os efeitos dos tratamentos avaliados empregando-se o teste F. Para situações nas quais se detectaram efeitos significativos dos tratamentos, buscou-se ajustar equações de regressão relacionando doses de nitrogênio e potássio aplicadas via fertirrigação (T1, T2, T3 e T4) com as variáveis resposta. Nas comparações de médias envolvendo todos os tratamentos, empregou-se o teste t de Student $(\alpha=0,05)$. Para comparações previamente estabelecidas entre tratamentos, testaram-se contrastes por meio do teste $t$ de Student $(\alpha=0,05)$.

\section{RESULTADOS E DISCUSSÃO}

Os resultados da análise de solo referente à amostragem prévia ao plantio encontram-se na Tabela 2. Observou-se que a aplicação de calcário dolomítico, em setembro de 2003, foi eficaz para elevar a saturação por bases, $\mathrm{Ca}^{2+} \mathrm{e} \mathrm{Mg}^{2+}$ trocáveis da camada de 0 a $20 \mathrm{~cm}$, que eram $31 \%, 7$ e $3 \mathrm{mmol} / \mathrm{dm}^{3}$, respectivamente, em

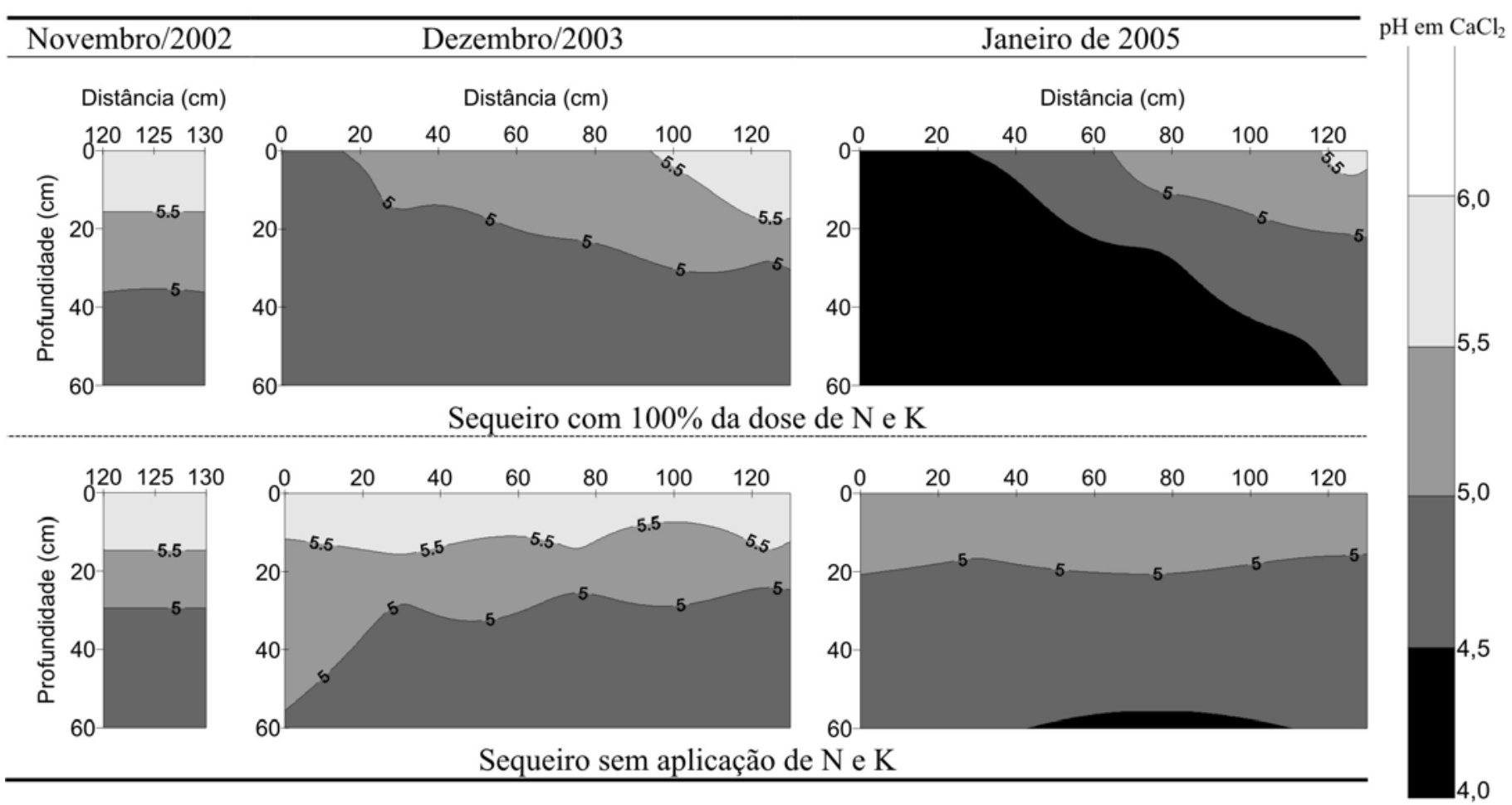

FIGURA 4 - pH $\left(\mathrm{CaCl}_{2}\right)$ do solo nas parcelas sob sequeiro em função dos tratamentos, camada amostrada (eixo vertical, cm) e distância da planta-mãe(eixo horizontal, $\mathrm{cm}$ ).

TABELA 1 - Tratamentos aplicados às unidades experimentais

\begin{tabular}{|c|c|}
\hline Tratamento & Descrição \\
\hline T1 & Irrigação sem aplicação de $\mathrm{N}$ e $\mathrm{K}$ \\
\hline $\mathrm{T} 2$ & Fertirrigação com $40 \%$ da dose de $\mathrm{N}$ e $\mathrm{K}^{(1)}$ \\
\hline T3 & Fertirrigação com $80 \%$ da dose de $\mathrm{N}$ e $\mathrm{K}^{(1)}$ \\
\hline $\mathrm{T} 4$ & Fertirrigação com $120 \%$ da dose de $\mathrm{N}$ e $\mathrm{K}^{(1)}$ \\
\hline T5 & Irrigação com $100 \%$ da dose de $\mathrm{N}$ e $\mathrm{K}^{(1)}$ via solo \\
\hline T6 & Sequeiro com $100 \%$ da dose de $\mathrm{Ne} \mathrm{K}^{(1)}$ via solo \\
\hline $\mathrm{T} 7$ & Sequeiro sem aplicação de N e K \\
\hline
\end{tabular}

TABELA 2 - Atributos químicos do solo de quatro camadas médias de cinco parcelas em seis blocos. Valores iniciais, amostragem, em novembro de 2002

\begin{tabular}{|c|c|c|c|c|c|c|c|c|}
\hline Camada & MO $^{(1)}$ & $\overline{\mathrm{pH}^{(2)}}$ & $\mathbf{P}_{\text {resina }}$ & $\mathbf{K}^{+}$ & $\mathrm{Ca}^{2+}$ & $\mathrm{Mg}^{2+}$ & $\mathbf{H}+\mathbf{A l}$ & $\mathbf{V}^{(3)}$ \\
\hline $\mathrm{cm}$ & $\mathrm{g} / \mathrm{kg}$ & & $\mathrm{mg} / \mathrm{dm}^{3}$ & $-\cdots$ & $\mathrm{mm}$ & $1 / \mathrm{dm}^{3}$ & --------- & $\%$ \\
\hline 0 a 5 & 10 & 5,8 & 42 & 3,0 & 23 & 15 & 16 & 70 \\
\hline 5 a 20 & 10 & 5,5 & 34 & 2,8 & 18 & 11 & 19 & 61 \\
\hline 20 a 40 & 7 & 4,8 & 18 & 2,3 & 11 & 5 & 26 & 41 \\
\hline 40 a 60 & 6 & 4,7 & 12 & 2,3 & 13 & 5 & 28 & 41 \\
\hline
\end{tabular}

(1)Matéria orgânica; (2)pH do solo medido em solução de $\mathrm{CaCl}_{2}$

$0,01 \mathrm{~mol} \mathrm{~L}^{-1}$, solo:solução $=1: 2,5(\mathrm{v} / \mathrm{v}) ;{ }^{(3)}$ saturação por bases. 
agosto de 2002.

Os efeitos dos tratamentos nos atributos químicos do solo, após cada ciclo de cultivo, são apresentados nas Tabelas 3 e 4. Tanto na amostragem ao final do primeiro (Tabela 3), como na do segundo ciclos (Tabela 4), observaram-se variações significativas nos atributos do solo em função dos tratamentos. Destacaram-se os efeitos dos tratamentos no $\mathrm{pH}$ do solo e no teor de $\mathrm{K}^{+}$trocável (Figuras 3 a 6).

Aumentos na dose dos fertilizantes, tanto aplicados via fertirrigação como na forma convencional, implicaram incrementos na acidez ( $\mathrm{pH} \mathrm{em} \mathrm{CaCl}_{2}$ e $\mathrm{H}+\mathrm{Al}$ ) do solo, principalmente até $20 \mathrm{~cm}$ de profundidade (Tabelas 3 e 4). Paralelo ao aumento na acidez, observou-se diminuição nos teores de $\mathrm{Ca}^{2+}, \mathrm{Mg}^{2+}$ e na saturação por bases (V\%). Esta acidificação é associada aos efeitos da adubação nitrogenada que favorece reações que produzem $\mathrm{H}^{+}$ (nitrificação) e a perda de cátions para camadas mais profundas, acompanhando o ânion $\mathrm{NO}_{3}^{-}$(Tisdale et al., 1985). Acidificação do solo decorrente da adubação nitrogenada também foi observada no cultivo de seringueira (Bataglia \& Santos, 1999), citros (Sanches et al., 1999), entre outros. Da mesma forma, Teixeira et al. (2001) constataram redução no pH do solo em resposta à adubação nitrogenada $\left(\mathrm{NH}_{4} \mathrm{NO}_{3}\right.$, em superfície) aplicada em bananal irrigado.

Observou-se que o impacto da adubação via fertirrigação no $\mathrm{pH}$ do solo foi proporcional à dose. Estimou-se que cada 100 $\mathrm{kg}$ de $\mathrm{N}$ aplicados anualmente via fertirrigação causaram redução de aproximadamente 0,08 unidade de $\mathrm{pH}$ no primeiro ciclo de cultivo e de 0,15 unidade, no segundo ciclo, na camada de 0 a 20 cm (Figura 7). A adubação convencional (T5 e T6), tanto na área irrigada (Figura 2), como sob sequeiro (Figura 3),

TABELA 3 - Atributos químicos do solo em função da fertirrigação e adubação convencional em quatro profundidades de amostragem. Amostragem: dezembro de 2003.

\begin{tabular}{|c|c|c|c|c|c|c|c|c|}
\hline Tratamento & MO & $\mathrm{pH}\left(\mathrm{CaCl}_{2}\right)$ & $\mathbf{P}_{\text {resina }}$ & $\mathbf{K}^{+}$ & $\mathrm{Ca}^{2+}$ & $\mathbf{M g}^{2+}$ & $\mathbf{H}+\mathbf{A l}$ & $\mathbf{V}$ \\
\hline & $\mathrm{g} / \mathrm{kg}$ & & $\mathrm{mg} / \mathrm{dm}^{3}$ & $\begin{array}{ll}----- \\
\end{array}$ & ------ mm & $\mathrm{m}^{3}--$ & ------- & $\%$ \\
\hline Irriga-dose 0 & $12 \mathrm{a}$ & $6,19 a$ & $52 \mathrm{a}$ & $1,6 \mathrm{~d}$ & $25 \mathrm{a}$ & $14 \mathrm{a}$ & $11 \mathrm{c}$ & $79 a$ \\
\hline Fertirriga-dose $40 \%$ & $12 \mathrm{a}$ & $5,96 b$ & $49 \mathrm{ab}$ & $1,9 \mathrm{~cd}$ & $23 \mathrm{ab}$ & $11 \mathrm{ab}$ & $13 b c$ & $73 \mathrm{ab}$ \\
\hline Fertirriga-dose $80 \%$ & $12 \mathrm{a}$ & $5,77 \mathrm{bc}$ & $46 a b c$ & $2,2 \mathrm{bc}$ & $23 \mathrm{ab}$ & $10 b$ & $14 \mathrm{~b}$ & $71 b c$ \\
\hline Fertirriga-dose $120 \%$ & $12 \mathrm{a}$ & $5,51 \mathrm{de}$ & $41 \mathrm{c}$ & $2,3 \mathrm{bc}$ & $21 \mathrm{abc}$ & $9 b$ & $16 \mathrm{a}$ & $66 \mathrm{~cd}$ \\
\hline Irriga-dose $100 \%$ via solo & $12 \mathrm{a}$ & $5,83 \mathrm{bc}$ & $45 \mathrm{bc}$ & $2,6 b$ & $22 \mathrm{abcb}$ & $11 \mathrm{ab}$ & $14 b$ & $71 b c$ \\
\hline Sequeiro-dose $100 \%$ & $12 \mathrm{a}$ & $5,36 \mathrm{e}$ & $43 \mathrm{bc}$ & $4,6 \mathrm{a}$ & $18 \mathrm{c}$ & $11 \mathrm{ab}$ & $17 \mathrm{a}$ & $63 d$ \\
\hline Sequeiro-dose 0 & $12 \mathrm{a}$ & $5,70 \mathrm{~cd}$ & $42 \mathrm{c}$ & $2,4 \mathrm{bc}$ & $19 b c$ & $11 \mathrm{ab}$ & $14 b$ & $67 \mathrm{bcd}$ \\
\hline $\mathrm{CV}(\%)$ & 12 & 6 & 22 & 33 & 30 & 43 & 18 & 13 \\
\hline Irriga-dose 0 & $10 \mathrm{a}$ & $5,89 \mathrm{a}$ & $38 \mathrm{ab}$ & $1,2 \mathrm{c}$ & $19 \mathrm{ab}$ & $12 \mathrm{a}$ & $14 \mathrm{c}$ & $68 \mathrm{ab}$ \\
\hline Fertirriga-dose $40 \%$ & $10 \mathrm{a}$ & $5,84 \mathrm{a}$ & $40 \mathrm{ab}$ & $1,4 \mathrm{bc}$ & $19 \mathrm{ab}$ & $11 \mathrm{ab}$ & $14 \mathrm{c}$ & $68 \mathrm{ab}$ \\
\hline Fertirriga-dose $80 \%$ & $11 \mathrm{a}$ & $5,80 \mathrm{ab}$ & $42 \mathrm{a}$ & $1,5 \mathrm{bc}$ & $21 \mathrm{a}$ & $12 \mathrm{a}$ & $14 \mathrm{c}$ & $70 \mathrm{a}$ \\
\hline Fertirriga-dose $120 \%$ & $11 \mathrm{a}$ & $5,67 \mathrm{abc}$ & $43 a$ & $1,7 \mathrm{~b}$ & $21 \mathrm{a}$ & $11 \mathrm{ab}$ & $15 \mathrm{abc}$ & $67 \mathrm{ab}$ \\
\hline Irriga-dose $100 \%$ via solo & $10 \mathrm{a}$ & $5,50 \mathrm{~cd}$ & $36 \mathrm{bc}$ & $1,7 b$ & $16 \mathrm{c}$ & $9 \mathrm{~b}$ & $17 \mathrm{a}$ & $60 c$ \\
\hline Sequeiro-dose $100 \%$ & $11 \mathrm{a}$ & $5,44 d$ & $37 \mathrm{ab}$ & $3,2 \mathrm{a}$ & $17 \mathrm{bc}$ & $9 b$ & $17 \mathrm{a}$ & $60 \mathrm{c}$ \\
\hline Sequeiro-dose 0 & $10 \mathrm{a}$ & $5,59 \mathrm{bcd}$ & $31 \mathrm{c}$ & $1,7 \mathrm{~b}$ & $16 \mathrm{bc}$ & $10 \mathrm{ab}$ & $16 \mathrm{bc}$ & $64 b c$ \\
\hline $\mathrm{CV}(\%)$ & 15 & 6 & 24 & 43 & 27 & 36 & 20 & 13 \\
\hline Irriga-dose 0 & $6 b$ & $4,82 \mathrm{a}$ & $26 \mathrm{a}$ & $1,8 b$ & $10 \mathrm{~b}$ & $7 \mathrm{a}$ & $22 \mathrm{ab}$ & $44 a b$ \\
\hline Fertirriga-dose $40 \%$ & $7 \mathrm{ab}$ & $4,71 \mathrm{a}$ & $27 \mathrm{a}$ & $1,6 \mathrm{~b}$ & $11 \mathrm{ab}$ & $6 a$ & $23 a b$ & $44 a b$ \\
\hline Fertirriga-dose $80 \%$ & $7 \mathrm{ab}$ & $4,74 a$ & $25 \mathrm{a}$ & $1,6 \mathrm{~b}$ & $11 \mathrm{ab}$ & $7 \mathrm{a}$ & $24 a$ & $45 \mathrm{ab}$ \\
\hline Fertirriga-dose $120 \%$ & $7 \mathrm{ab}$ & $4,64 a$ & $25 \mathrm{a}$ & $1,7 \mathrm{~b}$ & $10 b$ & $6 a$ & $24 \mathrm{a}$ & $42 b$ \\
\hline Irriga-dose $100 \%$ via solo & $8 \mathrm{a}$ & $4,71 \mathrm{a}$ & $27 \mathrm{a}$ & $2,0 \mathrm{~b}$ & $12 \mathrm{a}$ & $6 a$ & $23 \mathrm{ab}$ & $46 \mathrm{ab}$ \\
\hline Sequeiro-dose $100 \%$ & $7 \mathrm{ab}$ & $4,71 \mathrm{a}$ & $23 a$ & $2,6 \mathrm{a}$ & $11 \mathrm{ab}$ & $7 \mathrm{a}$ & $22 \mathrm{ab}$ & $48 \mathrm{a}$ \\
\hline Sequeiro-dose 0 & $7 \mathrm{ab}$ & $4,81 \mathrm{a}$ & $22 \mathrm{a}$ & $1,9 b$ & $13 a$ & $6 a$ & $20 b$ & $49 a$ \\
\hline $\mathrm{CV}(\%)$ & 19 & 7 & 44 & 37 & 32 & 35 & 19 & 20 \\
\hline Irriga-dose 0 & $7 \mathrm{a}$ & $4,63 a$ & $21 \mathrm{a}$ & $1,7 \mathrm{~d}$ & $12 \mathrm{c}$ & $6 b$ & $24 a$ & $46 b$ \\
\hline Fertirriga-dose $40 \%$ & $8 \mathrm{a}$ & $4,69 \mathrm{a}$ & $20 \mathrm{a}$ & $1,8 \mathrm{~cd}$ & $15 \mathrm{ab}$ & $6 b$ & $23 a$ & $50 \mathrm{ab}$ \\
\hline Fertirriga-dose $80 \%$ & $8 \mathrm{a}$ & $4,69 a$ & $23 a$ & $2,1 \mathrm{bc}$ & $14 \mathrm{abc}$ & $6 b$ & $23 a$ & $50 \mathrm{ab}$ \\
\hline Fertirriga-dose $120 \%$ & $7 a$ & $4,69 \mathrm{a}$ & $20 \mathrm{a}$ & $1,8 \mathrm{~cd}$ & $13 b c$ & $6 b$ & $23 a$ & $47 b$ \\
\hline Irriga-dose $100 \%$ via solo & $8 \mathrm{a}$ & $4,78 \mathrm{a}$ & $21 \mathrm{a}$ & $2,0 \mathrm{bcd}$ & $17 \mathrm{a}$ & $7 \mathrm{a}$ & $22 \mathrm{ab}$ & $53 a$ \\
\hline Sequeiro-dose $100 \%$ & $7 a$ & $4,68 \mathrm{a}$ & $19 a$ & $3,0 \mathrm{a}$ & $13 \mathrm{bc}$ & $7 \mathrm{a}$ & $22 \mathrm{ab}$ & $50 \mathrm{ab}$ \\
\hline Sequeiro-dose 0 & $8 \mathrm{a}$ & $4,82 \mathrm{a}$ & $17 \mathrm{a}$ & $2,2 b$ & $15 \mathrm{abc}$ & $7 \mathrm{a}$ & $20 b$ & $54 \mathrm{a}$ \\
\hline $\mathrm{CV}(\%)$ & 22 & 14 & 47 & 25 & 31 & 24 & 19 & 18 \\
\hline
\end{tabular}

Valores de uma mesma camada seguidos por letras iguais não diferem entre si, pelo teste $\mathrm{t}$ de Student $(p>0,05)$. 
causou decréscimo no $\mathrm{pH}$, especialmente na região mais próxima das plantas, refletindo o efeito da aplicação localizada dos fertilizantes. Para bananeiras, a acidificação causada pela adição de $\mathrm{N}$ representa risco à manutenção de produtividades elevadas no decorrer do tempo, pois recomenda-se manter a saturação por bases acima de $60 \%$. Além disso, sabe-se que as bananeiras exigem suprimento adequado de $\mathrm{Mg}$, especialmente em áreas adubadas com potássio (Moreira \& Hiroce, 1978; Lichtemberg \& Malburg, 1983; Delvaux, 1985).
Observou-se pH do solo mais elevado nos tratamentos sob irrigação em relação aos de sequeiro (Tabelas 3 e 4), principalmente nas camadas mais superficiais. Provavelmente, este efeito deveu-se à maior solubilização do calcário aplicado em setembro de 2002, determinada pela maior umidade disponível sob irrigação. Segundo Quaggio (2000), a taxa de solubilização dos carbonatos de cálcio e magnésio contidos nos calcários pode ser limitada pela falta de umidade do solo.

TABELA 4 - Atributos químicos do solo em função da fertirrigação e adubação convencional em quatro profundidades de amostragem. Amostragem: janeiro de 2005.

\begin{tabular}{|c|c|c|c|c|c|c|c|c|}
\hline Tratamento & MO & $\mathrm{pH}\left(\mathrm{CaCl}_{2}\right)$ & $\mathbf{P}_{\text {resina }}$ & $\mathbf{K}^{+}$ & $\mathrm{Ca}^{2+}$ & $\mathrm{Mg}^{2+}$ & $\mathbf{H}+\mathbf{A l}$ & $\mathbf{V}$ \\
\hline & $\mathrm{g} / \mathrm{kg}$ & & $\mathrm{mg} / \mathrm{dm}^{3}$ & \multicolumn{4}{|c|}{ 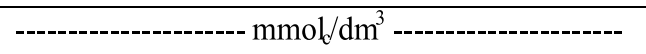 } & $\%$ \\
\hline Irriga-dose 0 & $12 \mathrm{a}$ & $6,19 a$ & $37 \mathrm{ab}$ & $1,3 \mathrm{~d}$ & $28 \mathrm{a}$ & $12 \mathrm{a}$ & $12 \mathrm{~d}$ & $77 \mathrm{a}$ \\
\hline Fertirriga-dose $40 \%$ & $13 \mathrm{a}$ & $6,11 \mathrm{ab}$ & $36 \mathrm{ab}$ & $1,3 \mathrm{~d}$ & $27 \mathrm{ab}$ & $10 \mathrm{ab}$ & $13 \mathrm{~d}$ & $75 \mathrm{ab}$ \\
\hline Fertirriga-dose $80 \%$ & $12 \mathrm{a}$ & $5,83 \mathrm{bc}$ & $36 a b$ & $1,6 \mathrm{~cd}$ & $24 b$ & $8 \mathrm{~cd}$ & $14 \mathrm{~cd}$ & $69 \mathrm{bc}$ \\
\hline Fertirriga-dose $120 \%$ & $12 \mathrm{a}$ & $5,45 \mathrm{~d}$ & $31 b$ & $1,7 \mathrm{~cd}$ & $19 \mathrm{c}$ & $8 \mathrm{~cd}$ & $17 \mathrm{bc}$ & $62 \mathrm{~d}$ \\
\hline Irriga-dose $100 \%$ via solo & $13 \mathrm{a}$ & $5,67 \mathrm{~cd}$ & $43 a$ & $1,9 \mathrm{c}$ & $24 b$ & $9 \mathrm{bc}$ & $16 \mathrm{bc}$ & $68 \mathrm{c}$ \\
\hline Sequeiro-dose $100 \%$ & $13 a$ & $5,07 \mathrm{e}$ & $39 a$ & $3,8 \mathrm{a}$ & $14 d$ & $7 \mathrm{~d}$ & $21 \mathrm{a}$ & $52 \mathrm{e}$ \\
\hline Sequeiro-dose 0 & $13 a$ & $5,39 d$ & $36 \mathrm{ab}$ & $2,7 b$ & $16 \mathrm{~cd}$ & $8 \mathrm{~cd}$ & $17 \mathrm{bc}$ & $59 d$ \\
\hline $\mathrm{CV}(\%)$ & 21 & 7 & 31 & 35 & 25 & 33 & 28 & 14 \\
\hline Irriga-dose 0 & $12 \mathrm{a}$ & $5,82 \mathrm{a}$ & $37 \mathrm{a}$ & $1,2 \mathrm{c}$ & $20 \mathrm{a}$ & $11 \mathrm{a}$ & $16 \mathrm{~d}$ & $66 a$ \\
\hline Fertirriga-dose $40 \%$ & $11 \mathrm{a}$ & $5,68 \mathrm{a}$ & $35 \mathrm{ab}$ & $1,2 \mathrm{c}$ & $19 \mathrm{ab}$ & $9 b c$ & $17 \mathrm{~cd}$ & $63 a$ \\
\hline Fertirriga-dose $80 \%$ & $10 \mathrm{a}$ & $5,58 \mathrm{a}$ & $35 \mathrm{ab}$ & $1,2 \mathrm{c}$ & $21 \mathrm{a}$ & $9 b c$ & $17 \mathrm{~cd}$ & $63 a$ \\
\hline Fertirriga-dose $120 \%$ & $11 \mathrm{a}$ & $5,19 \mathrm{~b}$ & $35 \mathrm{ab}$ & $1,5 \mathrm{bc}$ & $18 \mathrm{ab}$ & $7 \mathrm{~cd}$ & $21 \mathrm{ab}$ & $55 b$ \\
\hline Irriga-dose $100 \%$ via solo & $11 \mathrm{a}$ & $5,16 \mathrm{bc}$ & $32 \mathrm{ab}$ & $1,6 b c$ & $15 b c$ & $7 \mathrm{~cd}$ & $21 \mathrm{ab}$ & $53 \mathrm{bc}$ \\
\hline Sequeiro-dose $100 \%$ & $11 \mathrm{a}$ & $4,88 \mathrm{c}$ & $31 b$ & $2,9 \mathrm{a}$ & $12 \mathrm{c}$ & $6 \mathrm{~d}$ & $23 a$ & $47 \mathrm{c}$ \\
\hline Sequeiro-dose 0 & $10 \mathrm{a}$ & $5,16 \mathrm{bc}$ & $24 \mathrm{c}$ & $1,7 \mathrm{~b}$ & $13 \mathrm{c}$ & $7 \mathrm{~d}$ & $20 \mathrm{bc}$ & $52 \mathrm{bc}$ \\
\hline $\mathrm{CV}(\%)$ & 25 & 8 & 30 & 38 & 32 & 29 & 24 & 19 \\
\hline Irriga-dose 0 & $8 \mathrm{ab}$ & $4,81 \mathrm{a}$ & $22 \mathrm{ab}$ & $1,5 \mathrm{bc}$ & $11 \mathrm{a}$ & $6 a$ & $24 b$ & $45 \mathrm{a}$ \\
\hline Fertirriga-dose $40 \%$ & $8 \mathrm{ab}$ & $4,57 \mathrm{bc}$ & $24 \mathrm{ab}$ & $1,2 \mathrm{c}$ & $10 \mathrm{ab}$ & $6 a$ & $27 \mathrm{ab}$ & $39 \mathrm{ab}$ \\
\hline Fertirriga-dose $80 \%$ & $7 \mathrm{~b}$ & $4,66 \mathrm{ab}$ & $22 \mathrm{ab}$ & $1,2 \mathrm{c}$ & $12 \mathrm{a}$ & $6 a$ & $26 b$ & $42 \mathrm{a}$ \\
\hline Fertirriga-dose $120 \%$ & $8 \mathrm{ab}$ & $4,62 \mathrm{ab}$ & $26 a$ & $1,4 \mathrm{bc}$ & $13 a$ & $6 a$ & $26 b$ & $43 a$ \\
\hline Irriga-dose $100 \%$ via solo & $9 a$ & $4,47 b c$ & $23 \mathrm{ab}$ & $1,6 b$ & $13 a$ & $6 a$ & $30 \mathrm{a}$ & $40 \mathrm{ab}$ \\
\hline Sequeiro-dose $100 \%$ & $8 a b$ & $4,37 \mathrm{c}$ & $17 \mathrm{bc}$ & $2,3 a$ & $8 b$ & $4 b$ & $26 b$ & $35 b$ \\
\hline Sequeiro-dose 0 & $8 a b$ & $4,66 \mathrm{ab}$ & $14 \mathrm{c}$ & $1,4 \mathrm{bc}$ & $10 \mathrm{ab}$ & $5 \mathrm{ab}$ & $24 b$ & $42 \mathrm{a}$ \\
\hline $\mathrm{CV}(\%)$ & 27 & 7 & 45 & 41 & 34 & 32 & 21 & 24 \\
\hline Irriga-dose 0 & $7 b$ & $4,41 \mathrm{a}$ & $13 a$ & $1,4 \mathrm{~b}$ & $12 \mathrm{c}$ & $5 a$ & $32 \mathrm{ab}$ & $37 \mathrm{c}$ \\
\hline Fertirriga-dose $40 \%$ & $8 \mathrm{ab}$ & $4,44 a$ & $14 \mathrm{a}$ & $1,3 b$ & $14 \mathrm{bc}$ & $5 a$ & $33 a$ & $39 b c$ \\
\hline Fertirriga-dose $80 \%$ & $7 \mathrm{~b}$ & $4,58 \mathrm{a}$ & $17 \mathrm{a}$ & $1,3 b$ & $18 \mathrm{a}$ & $6 a$ & $26 b$ & $49 a$ \\
\hline Fertirriga-dose $120 \%$ & $7 b$ & $4,53 \mathrm{a}$ & $17 \mathrm{a}$ & $1,6 \mathrm{~b}$ & $17 \mathrm{ab}$ & $6 a$ & $28 \mathrm{ab}$ & $46 a b$ \\
\hline Adubo via solo & $9 \mathrm{a}$ & $4,46 a$ & $11 \mathrm{a}$ & $1,6 b$ & $13 b c$ & $5 a$ & $35 a$ & $38 \mathrm{bc}$ \\
\hline Sequeiro-dose $100 \%$ & $8 a b$ & $4,39 a$ & $15 \mathrm{a}$ & $2,5 \mathrm{a}$ & $14 \mathrm{bc}$ & $6 a$ & $28 \mathrm{ab}$ & $43 \mathrm{abc}$ \\
\hline Sequeiro-dose 0 & $8 a b$ & $4,56 a$ & $14 \mathrm{a}$ & $1,6 b$ & $15 \mathrm{abc}$ & $5 a$ & $28 \mathrm{ab}$ & $45 \mathrm{abc}$ \\
\hline $\mathrm{CV}(\%)$ & 24 & 8 & 90 & 40 & 37 & 31 & 35 & 30 \\
\hline
\end{tabular}

Valores de uma mesma camada seguidos por letras iguais não diferem entre si, pelo teste t de Student $(p>0,05)$. 
TABELA 5 - Contrastes entre os efeitos dos tratamentos no conteúdo de K disponível ( $\mathrm{kg} / \mathrm{ha})$ na camada de solo de 0 a $60 \mathrm{~cm}$ e valores $p$ associados, em dois ciclos de cultivo

\begin{tabular}{|c|c|c|c|c|}
\hline \multirow{2}{*}{ Descrição do contraste } & \multicolumn{2}{|c|}{ Primeiro ciclo } & \multicolumn{2}{|c|}{ Segundo ciclo } \\
\hline & $\mathbf{K}_{2} \mathbf{O}^{(1)}$ & Valor $p^{(2)}$ & $\mathrm{K}_{2} \mathrm{O}$ & Valor $p$ \\
\hline Efeito dos tratamentos em relação ao conteúdo de $\mathrm{K}$ inicial & --- kg/ha --- & & --- kg/ha --- & \\
\hline 1 Irrigação sem adubo ( $\mathrm{K}$ inicial-T1) & -227 & 0,0001 & -278 & $<0,0001$ \\
\hline 2 Fertirrigação $40 \%$ da dose ${ }^{(3)}$ (K inicial-T2) & -216 & $<0,0001$ & -324 & $<0,0001$ \\
\hline 3 Fertirrigação $80 \%$ da dose (K inicial-T3) & -217 & 0,0026 & -368 & $<0,0001$ \\
\hline 4 Fertirrigação $120 \%$ da dose (K inicial-T4) & -167 & 0,0019 & -245 & $<0,0001$ \\
\hline 5 Irrigação dose $100 \%$ (adubo via solo) (K inicial-T5) & -88 & 0,0952 & -201 & 0,0010 \\
\hline 6 Sequeiro dose $100 \%$ (K inicial-T6) & 119 & 0,2896 & -3 & 0,9771 \\
\hline 7 Sequeiro sem adubo (K inicial-T7) & -165 & 0,0074 & -258 & 0,0002 \\
\hline Contrastes entre tratamentos ao final dos ciclos de cultivo & & & & \\
\hline 8 Irrigação sem adubo vs. sequeiro sem adubo (T1-T7) & -117 & 0,0105 & -75 & 0,2287 \\
\hline 9 Fertirrigação $40 \%$ da dose vs. Irrigação sem adubo (T2-T1) & 17 & 0,6950 & -40 & 0,5163 \\
\hline 10 Fertirrigação $80 \%$ da dose vs. Irrigação sem adubo (T3-T1) & 61 & 0,1635 & -38 & 0,5321 \\
\hline 11 Fertirrigação $120 \%$ da dose vs. irrigação sem adubo (T4-T1) & 54 & 0,2210 & 27 & 0,6607 \\
\hline 12 Irrigação dose $100 \%$ (adubo via solo) vs. irrigação sem adubo (T5-T1) & 119 & 0,0091 & 57 & 0,3526 \\
\hline 13 Irrigação dose $100 \%$ (adubo via solo) vs. sequeiro dose $100 \%$ (T5-T6) & -297 & $<0,0001$ & -288 & $<0,0001$ \\
\hline 14 Sequeiro dose $100 \%$ vs. sequeiro sem adubo (T6-T7) & 300 & $<0,0001$ & 271 & 0,0001 \\
\hline
\end{tabular}

Valores em negrito assinalam contrastes significativos, a $5 \%$ de probabilidade (teste $\mathrm{t}$ de Sudente, $p<0,05)$. ${ }^{(1)}$ Estimativa do conteúdo de $\mathrm{K}$ disponível na camada do solo de 0 a $60 \mathrm{~cm}$, considerando: $1 \mathrm{mmol}_{\mathrm{c}}$ de $\mathrm{K}^{+}=0,04709 \mathrm{~g} \mathrm{de} \mathrm{K}_{2} \mathrm{O}$ e densidade do solo $=1,0 \mathrm{~kg} / \mathrm{dm}^{3} ;$ valores negativos indicam perdas, e positivos, acumulação de potássio no perfil do solo. ${ }^{(2)}$ Probabilidade (varia de zero a um) de que os resultados possam ter ocorrido devido ao acaso; indica a significância estatística do contraste. ${ }^{(3)}$ Dose de $\mathrm{K}=400 \mathrm{~kg} / \mathrm{ha} / \mathrm{ano}$ de $\mathrm{K}_{2} \mathrm{O}$.

Ao final do primeiro ciclo de produção (dezembro/2003) e do segundo (janeiro/2005), o teor de $\mathrm{K}^{+}$trocável apresentou variação significativa em função dos tratamentos, especialmente nas camadas de 0 a $5 \mathrm{~cm}$ e de 5 a $20 \mathrm{~cm}$ (Tabelas 3 e 4), e nas amostras mais próximas das plantas (Figuras 5 e 6 ). A aplicação de adubo sólido na superfície do solo (T6) determinou significativo acúmulo de potássio nas camadas até $20 \mathrm{~cm}$ e na região mais próxima ao pseudocaule das plantas. Os efeitos da adubação potássica via fertirrigação foram mais difusos, visto que os adubos são espalhadas numa área de solo maior do que a coberta pela adubação convencional.

$\mathrm{Na}$ amostragem realizada em janeiro de 2005 (Tabela 4), observou-se diminuição nos teores de $\mathrm{K}^{+}$trocável em relação à situação inicial (Tabela 2) e aos resultados de 2003 (Tabela 3). Provavelmente, esta diminuição está associada à coincidência da última época de amostragem (final de janeiro) com um período de chuvas intensas. A precipitação acumulada entre dezembro de 2004 e janeiro de 2005 foi superior a 500mm (Figura 1). Para iniciar amostragem do solo, foi necessário esperar alguns dias, o que aumentou o período entre a última adubação e a coleta. Depois, houve várias interrupções na coleta, pois o solo, freqüentemente, apresentava umidade excessiva. Diferentemente, a amostragem em 2003 foi antecedida por inverno relativamente seco.

Para quantificar a variação na disponibilidade de potássio no perfil do solo (de 0 a $60 \mathrm{~cm}$ ), em função dos tratamentos, foram estabelecidos os contrastes apresentados na Tabela 5. Comparando-se a quantidade de potássio disponível no solo após cada ciclo de cultivo com a disponibilidade prévia à instalação do experimento, observou-se redução, especialmente nos tratamentos sob irrigação (Contrastes 1 a 4). Em sequeiro, com a aplicação de potássio, a variação não foi significativa (Contraste 6). Sob sequeiro e sem adubação potássica, ocorreram perdas de potássio em relação ao conteúdo de $\mathrm{K}$ inicial (Contraste 7).

Ao se compararem os efeitos dos tratamentos no conteúdo de $\mathrm{K}$ do perfil do solo, constata-se que a influência da irrigação no aumento das perdas é significativo, tanto sem adubação (Contraste 8), como com aplicação de K (Contraste 13). Todos os tratamentos de fertirrigação (doses) não causaram aumentos significativos em relação ao tratamento irrigado sem adubação (Contrastes 9, 10 e 11). Sob sequeiro, o efeito da adubação na quantidade de $\mathrm{K}$ foi significativo (Contraste 14), determinando incremento de aproximadamente $300 \mathrm{~kg} / \mathrm{ha}$ de $\mathrm{K}_{2} \mathrm{O}$ em relação ao tratamento sem adubação.

A irrigação causou perdas significativas de potássio para camadas subsuperficiais, mesmo com seu manejo visando a somente repor a evapotranspiração da cultura. $\mathrm{O}$ solo da área experimental apresenta significativa movimentação de água no seu perfil, como descrito por Bertoni et al. (1976). Estes autores relataram que até $51,4 \%$ da água que chega ao solo por precipitação pode ser perdido por percolação ao longo de um ano. Com irrigação, o que implica maior disponibilidade de água durante todo o ano, as perdas de potássio aumentaram. Soma-se ao incremento na lixiviação determinado pela irrigação, a possível maior acumulação de potássio na biomassa das plantas e exportação por meio da produção em relação ao sequeiro, como descrito por Teixeira et al. (2001). 

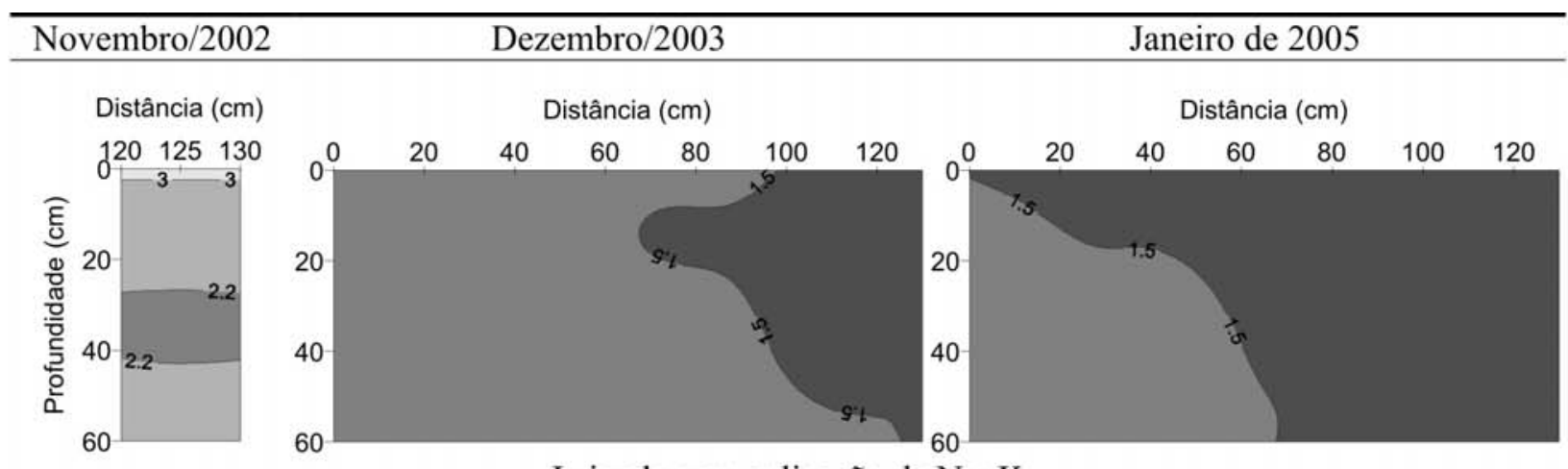

Irrigado sem aplicação de $\mathrm{Ne} \mathrm{K}$
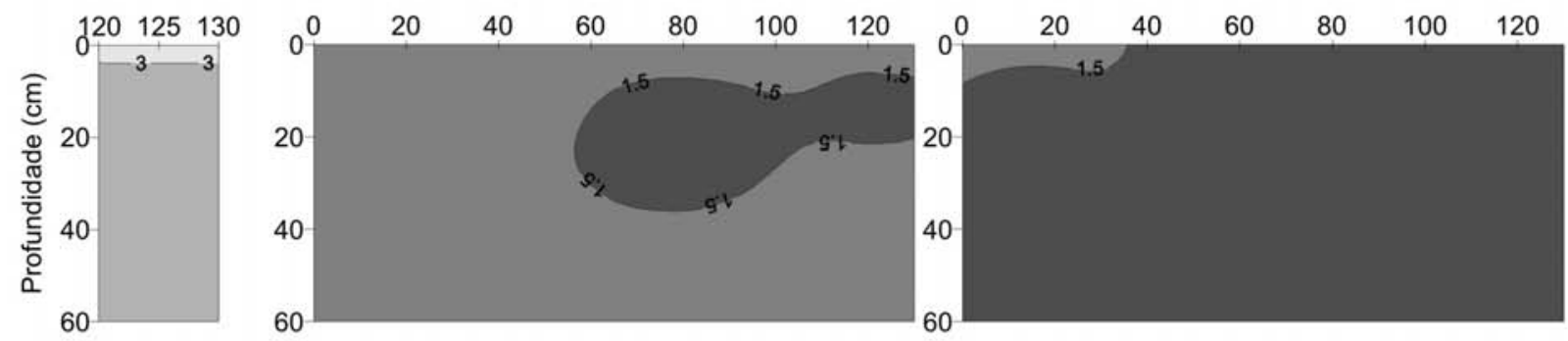

Fertirrigação com $40 \%$ da dose de $\mathrm{N}$ e $\mathrm{K}$
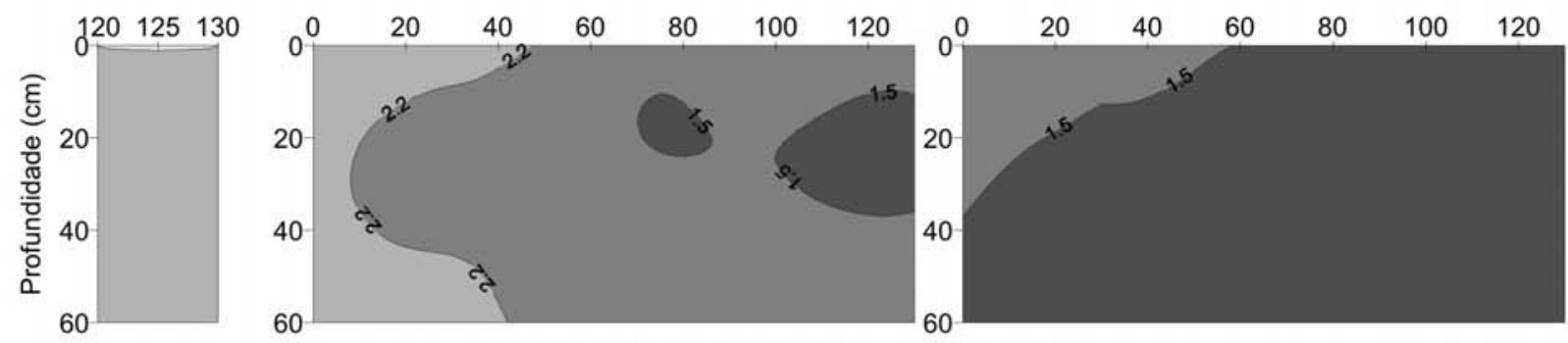

Fertirrigação com $80 \%$ da dose de $\mathrm{N}$ e $\mathrm{K}$
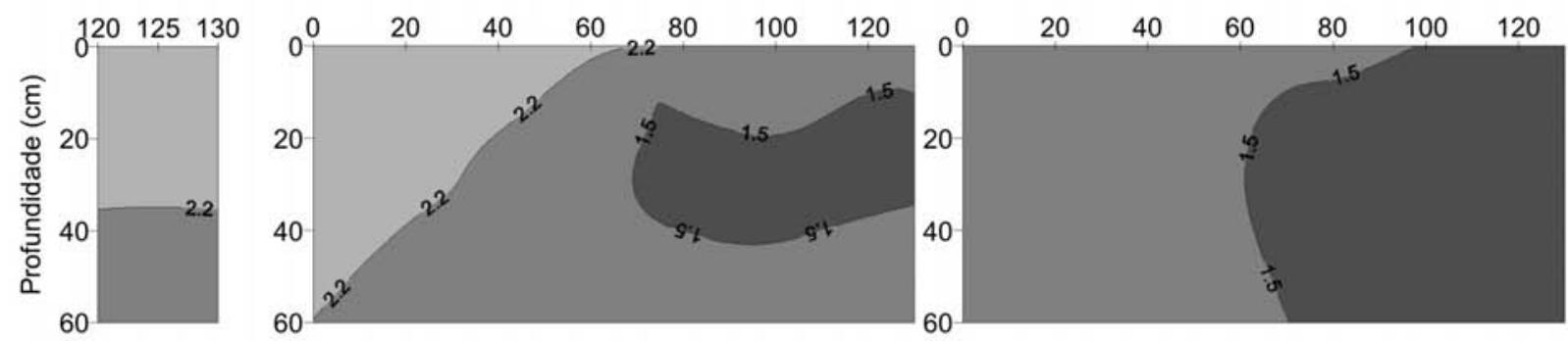

Fertirrigação com $120 \%$ da dose de $\mathrm{N}$ e K
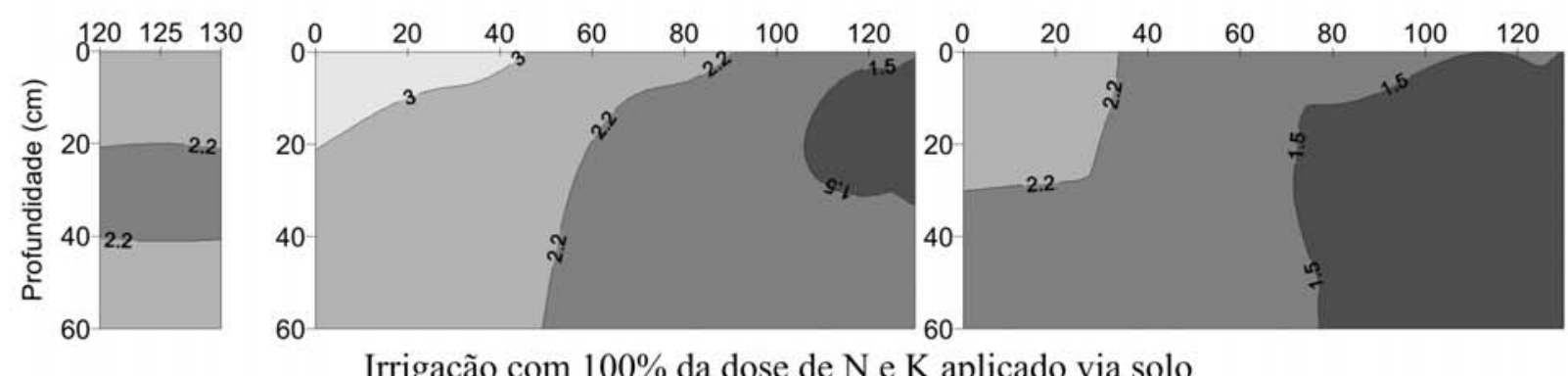

FIGURA 5 - $\mathrm{K}^{+}$trocável nas parcelas sob irrigação em função dos tratamentos, camada amostrada (eixo vertical, cm) e distância da planta-mãe(eixo horizontal, cm). 

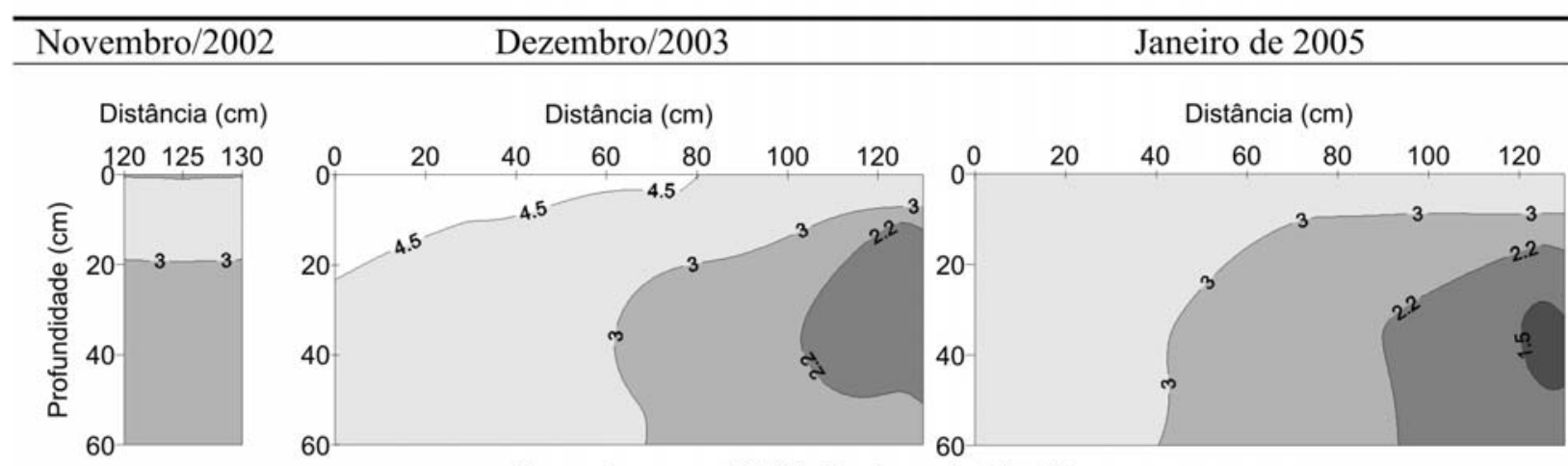

$\mathrm{K}^{+}$trocável $\left(\mathrm{mmol}_{\mathrm{d}} / \mathrm{dm}^{-3}\right)$

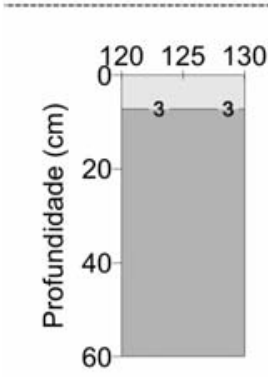

\section{Sequeiro com $100 \%$ da dose de $\mathrm{Ne} \mathrm{K}$}

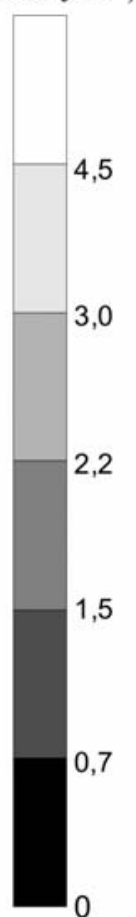

FIGURA 6 - $\mathrm{K}^{+}$trocável nas parcelas sob sequeiro em função dos tratamentos, camada amostrada (eixo vertical, cm) e distância da planta-mãe(eixo horizontal, cm).

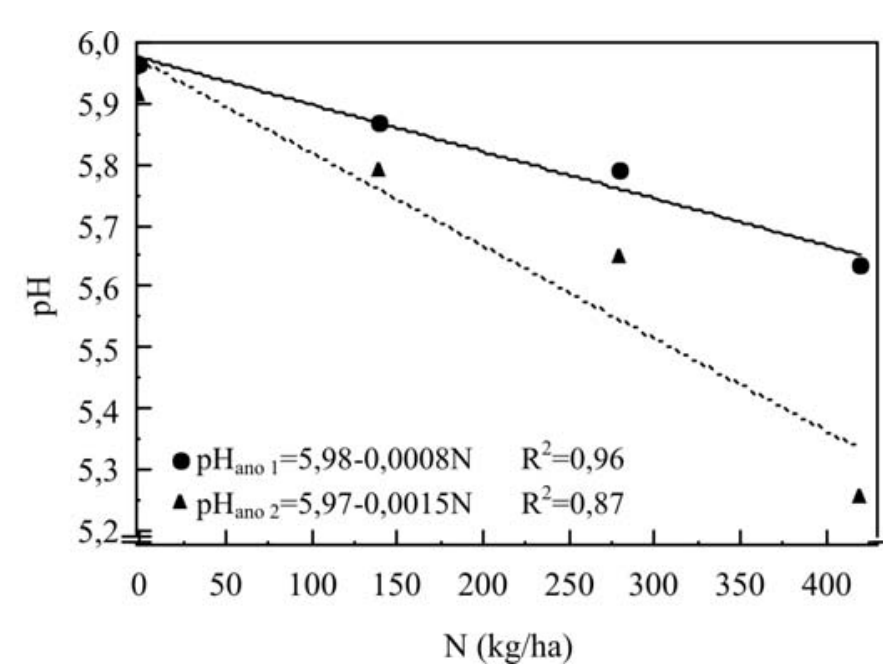

FIGURA 7 - Variação no $\mathrm{pH}\left(\mathrm{CaCl}_{2}\right)$ do solo na camada de 0 a $20 \mathrm{~cm}$ em função da aplicação de $\mathrm{N}$ via fertirrigação, em dois ciclos de cultivo de bananeira.

\section{CONCLUSÕES}

1. A adubação (fertirrigação e convencional) aumentou a acidez do solo.

2. Sob fertirrigação, a acidificação do solo foi proporcional à dose de adubo.

3. Adubação convencional determinou acúmulo de $\mathrm{K}$ nas camadas superficiais do solo e na área mais próxima às plantas.

4. Os efeitos da fertirrigação nos atributos químicos do solo foram mais difusos do que os da adubação convencional.

5. No cultivo de bananeiras sob irrigação, perdeu-se mais potássio para camadas subsuperficiais do que em sequeiro.

\section{REFERÊNCIAS}

ANDRIGUETO, J. R.; KOSOSKI, A.R. (Org.). Marco legal da produção integrada de frutas no Brasil. Brasília: MAPA/ SARC, 2002.60p.

BATAGLIA, O.C.; SANTOS, W.R. Efeitos da adubação NPK na fertilidade do solo, nutrição e crescimento da seringueira. Revista Brasileira de Ciência do Solo, Viçosa, v.23, p.88190, 1999.

BERTONI, J.; LOMBARDI NETO, F.; BENATTI JÚNIOR, R. Estudo, em lisímetros monolíticos, de perdas de água e evapotranspiração em três tipos de solos sob diferentes condições de uso.Bragantia, Campinas, v.35, n.12, p.123145, 1976 
CUNHA, J.F.; FRAGA JR, C. Efeito da adubação mineral, orgânica e calagem, na produção da bananeira em várzea litorânea de Caraguatatuba - Estado de São Paulo. Bragantia, Campinas, v.22, p.159-68, 1963.

DELVAUX, B. Soils. In: GOWEN, S. (Ed.). Bananas and plantains. London: Chapman \& Hall, 1995. p.230-57.

DOORENBOS, J.; KASSAM, A.H. Yield response to water. Rome: FAO, 1979. 193p.

FRIZZONE, J.A.; BOTREL, T.A. Aplicação de fertilizantes via água de irrigação. In: SIMPÓSIO BRASILEIRO SOBRE FERTILIZANTES FLUIDOS. Piracicaba: ESALQ, CENA, POTAFOS, 1994. p.227-60.

GALLO, J.R.; BATAGLIA, O.C.; FURLANI, P.R.; HIROCE, R.; FURLANI, A.M.C.; RAMOS, M.T.B.; MOREIRA, R.S. Composição química inorgânica da bananeira (Musa acuminata Simmonds, cultivar Nanicão). Ciência e Cultura, São Paulo,. v.24, p.70-9, 1972.

GODEFROY, J.; DORMOY, M. Dynamique des éléments mineraux fertilisants dans un ferrisol de Martinique sous culture bananière. Application à la programation de la fumure. Fruits, Paris, v.45, n.2, p.93-101, 1990.

HAGIN, J.; TUCKER, B. Fertilization of dryland and irrigated soils. Berlin: Springer-Verlag, 1982. 190p.

JACOB, A.; UEXKÜLL, H.von. Fertilizer use: nutrition and manuring of tropical crops. Hannover: Verlagsgesellschaft für Ackerbau, 1958. p.349-65.

LEPSCH, I.F.; VALADARES, J.M.A.S. Levantamento pedológico detalhado da Estação Experimental de Pindorama, SP. Bragantia, Campinas, v.35, n.1, p.13-40, 1976.

LICHTEMBERG, L.A.; MALBURG, J.L. Controle do azul da bananeira pela aplicação de calcário dolomítico. Florianópolis: EMPASC, 1983. 7p. (Comunicado Técnico, 67)

MOREIRA, R.S. Banana: teoria e prática de cultivo. 2.ed. São Paulo: Fundação Cargill, 1999. (CD-ROM)

MOREIRA, R.S.; HIROCE, R. Diagnose do "Azul-da-bananeira" no litoral Sul Paulista. Bragantia, Campinas, v.37, p.59-63, 1978.

OLIVEIRA, J.B.; CAMARGO, M.N.; ROSSI, M.; CALDERANO FILHO, B. Mapa pedológico do Estado de São Paulo: legenda expandida. Campinas: IAC; Rio de Janeiro: EMBRAPASolos, 1999. 64p.: mapa.

QUAGGIO, J.A. Acidez e calagem em solos tropicais. Campinas: Instituto Agronômico, 2000. 111p.

RAIJ, B. van; ANDRADE, J.C.; CANTARELLA, H.; QUAGGIO, J.A. (Ed.). Análise química para avaliação da fertilidade de solos tropicais. Campinas: IAC, 2001. 285p.

SANCHES, A.C.; SILVA, A.P.; TORMENA, C.A.; RIGOLIN, A.T. Impacto do cultivo de citros em propriedades químicas, densidade do solo e atividade microbiana de um podzólico Vermelho-Amarelo. Revista Brasileira de Ciência do Solo, Viçosa, v.23, p.91-99, 1999.

SRINIVAS, K. Growth, yield, and quality of banana in relation to $\mathrm{N}$ fertigation. Tropical Agriculture, Trinidad, v.74, n.4, p.2604, 1997.
STEWART, L.; CAMPAGNOLO, D.; DANIELLS, J.; LEMIN, C.; GOEBEL, R.; PINESE, B.; PETERSON, R.; PETERSON, R.; EVANAS, D.; PATTSON, T., ARMOUR, J., GUNTHER, M . Tropical banana information kit. Nambour: Queensland Department of Primary Industries, 1998. (Serie: Agrilink)

TEIXEIRA, L.A.J. Tópicos de nutrição e adubação de bananeira. In: REUNIÃO ITINERANTE DE FITOSSANIDADE DO INSTITUTO BIOLÓGICO, 13., 2005, Registro - SP. Cultura da banana... São Paulo: Instituto Biológico, 2005. p. 79-94.

TEIXEIRA, L.A.J.; NATALE, W.;RUGGIERO, C. Alterações em alguns atributos químicos do solo decorrentes da irrigação e adubação nitrogenada e potássica em bananeira após dois ciclos de cultivo. Revista Brasileira de Fruticultura, Jaboticabal, v.23, p.684-689, 2001.

TEIXEIRA, L.A.J.; SPIRONELLO, A.; QUAGGIO, J.A.; FURLANI, P. Banana. In: RAIJ, B. van et al. (Ed.). Recomendações de adubação e calagem para o Estado de São Paulo. 2.ed.rev. Campinas: IAC, 1997. p.131-2. (BT, 100)

TISDALE, S.L., NELSON, W., BEATON, J.D. Soil fertility and fertilizers. $4^{\text {th }}$ ed. New York: Macmillan Publishing Company, 1985.754p.

UEXKÜLL, H.R. von. Potassium nutrition of some tropical plantation crops. In: MUNSON, R.D. (Ed.) Potassium in agriculture. Madison: ASA/CSSA/SSSA, 1985. p.929-54. 